\title{
Critically Discuss the Effects of Sleep on Long-Term Memory
}

\author{
Chi-Fai Lo ${ }^{1,2,3}$ \\ ${ }^{1}$ Institute of Theoretical Physics and Department of Physics, The Chinese University of Hong Kong, Hong Kong, China \\ ${ }^{2}$ Department of Psychology, Sociology and Politics, Sheffield Hallam University, Sheffield, United Kingdom \\ ${ }^{3}$ Social and Human Sciences Section, SCOPE, City University of Hong Kong, Hong Kong, China \\ Email: edcflo@gmail.com
}

How to cite this paper: Lo, C.-F. (2018) Critically Discuss the Effects of Sleep on Long-Term Memory. Psychology, 9, 561-569. https://doi.org/10.4236/psych.2018.94034

Received: February 21, 2018

Accepted: April 6, 2018

Published: April 9, 2018

Copyright (C) 2018 by author and Scientific Research Publishing Inc. This work is licensed under the Creative Commons Attribution International License (CC BY 4.0).

http://creativecommons.org/licenses/by/4.0/

\begin{abstract}
In our modern societies, sleep is commonly viewed as a luxury rather than a necessity, and should be kept at a strict minimum to enhance productivity. However, recent empirical studies reveal that sleep does play a critical role in our learning and memory; in fact, it has been shown that good sleep quality, feeling rested at school and having a distinct bed time have been associated with better functioning at school. Although consensus on sleep's contribution to the active processing of newly acquired memories has been established now, the question about exactly what underlying mechanisms are involved in the sleep-memory connection still remains unclear. This paper will critically discuss how sleep affects learning and memory with reference to current research findings.
\end{abstract}

\section{Keywords}

Sleep, Memory, Learning, Acquisition, Consolidation, Retrieval, Active System Consolidation Theory, Synaptic Homeostasis Theory

\section{Introduction}

The eye-catching title "Well-rested children do better at school" of an article posted on the webpage "Neuro-hit or neuro-myth?" of the Centre for Educational Neuroscience (CEN) in London definitely draws the attention of each parent (CEN, 2017). At first glance such an idea is never foreign to us because almost every one of us has experienced that being tired does hinder both our physical and mental functioning. Indeed, our family doctors always remind us that sleep plays a crucial role in memory, and that the quantity and quality of sleep profoundly affect our learning and memory (Harvard Health, 2012, 2014 \& 
2017). Learning is a complex cognitive process which requires the brain to encode new memories and put them in long-term storage so that they can be called upon for future purposes (Hill et al., 2007). Empirical research findings indicate that learning and memory involve three stages, namely acquisition, consolidation and retrieval (Hill et al., 2007; Rasch \& Born, 2013; Stickgold, 2013; Feld \& Diekelmann, 2015; Watson \& Buzaki, 2015). Acquisition is the process of encoding new information into memory. These newly acquired memories are fragile and unstable, so they need to be strengthened and reorganized for long-term storage (i.e. consolidation). Consolidation is important because its disruption leads to forgetting. Lastly, retrieval of information from storage involves either calling something to mind without any external stimulus reminder or remembering triggered by an external stimulus. All these three stages are necessary for proper memory function; acquisition and retrieval occur only during wakefulness whilst consolidation takes place during sleep (Hill et al., 2007; Feld \& Diekelmann, 2015).

Even though consensus on sleep's role in promoting the consolidation of newly acquired memories has been established now, the question about exactly what underlying mechanisms are involved in the sleep-memory connection still remains unresolved (Hill et al., 2007; Kopasz et al., 2010; De Bruin et al., 2017; CEN, 2017). It is thus the aim of this paper to critically discuss how sleep affects learning and memory with reference to current research findings.

\section{Sleep's Role for Memory Consolidation}

Every day humans spend about one-third of their lives on sleep but the purpose or functioning of sleep is still not entirely understood. Sleep not only is a basic human drive but also is a universal behaviour across the animal kingdom. Basically, sleep consists of two phases, namely the rapid eye movement (REM) phase and non-rapid eye movement (NREM) phase, and there are four stages in the NREM phase, of which the third and fourth are collectively known as the slow wave sleep (SWS) stage due to the presence of a slow wave electroencephalogram (EEG) pattern (Hill et al., 2007; Schulz, 2008; Alger et al., 2014; Feld \& Diekelmann, 2015). The SWS stage is characterised by a predominance of vagal activity with slowing and regularising of cardio-respiratory rates. Children in the SWS stage are difficult to rouse and are said to be in a state of "deep sleep". One night of sleep usually involves four or five sleep cycles, each of which is a progression through various stages of NREM sleep and REM sleep, each lasting for about 90 minutes (Hill et al., 2007; Billiard, 2008; Alger et al., 2014; Feld \& Diekelmann, 2015).

\subsection{Active System Consolidation Theory}

In accordance with the active system consolidation theory, which is one of the most widely studied models of sleep's role for memory consolidation, an active neuronal replay of memory representations takes place during the stage of SWS 
so as to strengthen the memory traces encoded during prior wakefulness (Diekelmann \& Born, 2010; Rasch \& Born, 2013; Oudiette \& Paller, 2013). Empirical supporting evidence shows that sleep following learning boosts a significant increase of synaptic spines specifically associated with preceding learning experience (Euston \& Steenland, 2014; Yang et al., 2014). Such a neuronal replay was first observed in rats, but recently signs of reactivation were also found in humans using the functional magnetic resonance imaging (fMRI). In these experimental studies participants learned tasks that activated specific brain regions, and similar activation patterns were then re-expressed in the hippocampus and cortex during the subsequent stage of SWS (Maquet et al., 2000; Peigneux et al., 2004; Diekelmann \& Born, 2010). The fMRI results suggested that the hallmark SWS oscillation (large amplitude waves $<1 \mathrm{~Hz}$ in the EEG) generated in cortical areas was responsible for coordinating the replay in the hippocampus, subsequently enabling the gradual transfer of the transient memory representations to their long-term storage sites within the cortex (for retrieval at a later point).

Although memory reactivation also occurs during wakefulness and REM sleep, yet the specific combination of the oscillatory environment found during the SWS stage seems to be responsible for the consolidation through reactivation in the hippocampus and cortex (Diekelmann \& Born, 2010). In addition to strengthening memories, sleep is found to reorganize memories to facilitate generalization and the abstraction of the gist from encoded information as well (Gomez et al., 2006; Durrant et al., 2011; Lewis \& Durrant, 2011; Inostroza \& Born, 2013; Feld \& Diekelmann, 2015). By conducting a study on a number reduction task in which participants tried to discover a hidden rule via performing a series of numerical transformations in order to find a short cut to solve the task, Wagner et al. (2004) found that sleep could even help gain insight and find new solutions to problems.

\subsection{Synaptic Homeostasis Theory}

Another very popular theory of the function of sleep for memory is the synaptic homeostasis theory (Tononi \& Cirelli, 2003, 2006, 2014). During wakefulness rising demands of space and energy in the brain are caused by the widespread synaptic potentiation occurring at encoding of information. In order to avoid breaching the limits of the encoding capabilities of the brain, sleep is essential to maintain basic brain functioning via a homeostatic mechanism known as synaptic downscaling that renormalizes synaptic weights (Cirelli \& Tononi, 2008; Tononi \& Cirelli, 2014). Thus, overall synaptic spines and markers for synaptic potentiation increase during wakefulness and decrease across periods of sleep (Vyazovskiy et al., 2008; Maret et al., 2011). In other words, sleep seems to play a similar role as the defragmenter and disk clean-up function of a personal computer. As a result, an improvement of learning after a period containing sleep is expected, compared to a period containing only wakefulness (McDermott et al., 
In a nap study in which one group of participants was allowed to take a nap in between two learning sessions and another group stayed awake, Mander and co-workers demonstrated substantial deterioration in encoding capability across the day in the wake participants and that those who took a nap could even slightly improve encoding performance at the second session (Mander et al., 2011). Yoo and co-workers also observed the same impairments associated with reduced hippocampal activation occurring to participants who were sleep-deprived for one night (Yoo et al., 2007). In addition, recent use of fMRI in sleep-deprived healthy young adults participating in a verbal learning task revealed decreased hippocampal activity and that these sleep-deprived adults performed significantly worse in the task, compared to controls who experienced normal sleep (Drummond et al., 2000). Beyond question sleep deprivation does have a significant negative impact on the consolidation and accurate retrieval of memories. Accordingly, the efficiency of the system of adaptation, learning and memory is indeed controlled by sleep's balancing effects.

\subsection{Two-State Model}

In spite of their popularity, these two theories seem to be conflicting with each other at the level of the synapse. In particular, the consolidation theory requires strengthening selected synaptic connections during sleep so as to consolidate memories whereas the homeostasis theory anticipates that synapses are generally weakened. In order to reconcile the seemingly opposing views of synaptic homeostasis and consolidation, Watson and Buzsaki (2015) put forward a theory of sleep that involves the division of labour between two states of sleep, namely the REM state and non-REM state. It is suggested that the REM sleep may contribute to the homeostatic weakening of overworked synapses, and that in the non-REM state a prominent and transient oscillatory rhythm called the sharp-wave ripple (SPW-R) provides a perfect mechanism for the precise consolidation of behaviourally relevant memories across many structures of the brain. The SPW-R, which is a brief ( 50 - $150 \mathrm{~ms}$ ) electrical rhythm generated by an intrinsic self-organizing process in the hippocampus, is the key player in the memory consolidation process of waking experience (Buzsaki, 1989). Since the weakening of synapses generally covers the entire duration of sleep whilst compressed sequence replay of waking experience vanishes after thirty to sixty minutes (Wilson \& McNaughton, 1994), it seems to be possible that the REM and SWS play different but complementary roles in the sleep-memory process. In other words, sleep consists of a pair of special components, i.e. SWS and REM, which work together to prepare and clean the learning and memory system while retaining important information for later use (Watson \& Buzsaki, 2015). On the contrary, both the homeostasis and consolidation theories are mute on the role of REM sleep and unable to account for the complex choreography of the cyclic SWS-REM sleep process. Consequently, Watson and Buzsaki's theory 
actually unifies the two main theories of sleep that promotes both optimal knowledge retention and waking brain function.

\section{How Much Sleep Is Needed?}

If sleep deprivation is negatively associated with learning and memory, then how much sleep is necessary for memory consolidation? In other words, how can we optimize sleep's beneficial influence on memory? As expected, the timing of sleep does influence sleep's effect on memory; a shorter interval between sleep and learning enhances the effect of sleep on memory (Gais et al., 2006; Talamini et al., 2008; Payne et al., 2012). For instance, sleep that follows within 3 hours after encoding is more beneficial to the consolidation of English-German vocabulary than sleep following after 10 hours (Gais et al., 2006). Several studies have also shown that declarative memory can benefit from rather short periods (about 3 hours) of sleep (Yaroush et al., 1971; Barrett \& Ekstrand, 1972; Fowler et al., 1973; Plihal \& Born, 1997; Tucker \& Fishbein, 2009) or even naps (Lahl et al., 2008). As found in a study by Lahl et al. (2008), a brief period of sleep (approximately 6 minutes) facilitated superior recall of a learned list of words compared to remaining awake, but this effect was not as effective as obtaining a nap of 35 minutes. However, the brief nap's benefit was found to be temporary and not indicative of true memory consolidation (Alger et al., 2012). Hence, even though short intervals of sleep can help the initial consolidation of new memories, naps cannot replace a good night's sleep for longer periods of sleep provide better outcomes (Diekelmann et al., 2012).

Likewise, sleep might benefit children more than adults. In a study that tried to train adults and children who are 8 - 11 years old to press a specific sequence of buttons on a button-box, Wilhelm and co-workers (2013) observed that while both groups of participants gained more explicit awareness of the sequence after sleep compared to a wake interval, children clearly outperformed the adults after sleep. Similar observations of this beneficial effect of sleep on knowledge were also found in highly demanding education such as medical school (Ahrberg et al., 2012; Genzel et al., 2013). A questionnaire study indicated that sleep behaviour turned out to be the strongest predictor for the final grade in the medical examination (Genzel et al., 2013). Accordingly, "Well-rested children do better at schoop' might not be a myth at all, and improving sleep in children and students might be a promising target to improve school performance (Ribeiro \& Stickgold, 2014).

\section{Discussion}

Consensus on sleep's contribution to the active processing of newly acquired memories is now well established. Mounting empirical evidence indicates that during sleep the brain consolidates the newly acquired memories and integrates them into established knowledge networks for long-term storage. Sleep also helps renew the capacity of the brain for new learning. In addition to simply 
preserving memories, sleep promotes the flexible recombination of information, resulting in gist extraction and insight. Moreover, both nocturnal and daytime sleep episodes of varying lengths have been found to benefit memory processing, whereas sleep deprivation causes profound impairments in abstract and complex tasks involving higher brain functions. Therefore, sleep is in fact not idle time; instead, it is an active state.

As a result, sleep should be viewed as a necessity and not a luxury because it skilfully helps monitor our brain to work at its best. Improved sleeping conditions will thus enhance overall productivity to a larger extent than increasing the mere presence at work. For students it is probably of utmost importance to have a sufficient amount of sleep rather than to skip sleep in order to have more hours to study for tests and examinations. Nevertheless, further studies are badly needed for systematic investigations on the impact of sleep on distinct memory systems (both declarative and non-declarative) as well as for possible development of novel strategies concerning the interplay between sleep and memory in children and adolescents. Furthermore, in modern societies, sleep is increasingly vulnerable to disruption from features of our environment such as light and noise pollution, so it is essential to assess the amount of sleep deprivation that can be tolerated in order to have a better understanding of potential compensatory mechanisms.

\section{Acknowledgements}

The author would like to thank Dr. Anna Maria di Betta for her useful comments and suggestions.

\section{References}

Ahrberg, K., Dresler, M., Niedermaier, S., Steiger, A., \& Genzel, L. (2012). The Interaction between Sleep Quality and Academic Performance. Journal of Psychiatric Research, 46, 1618-1622. https://doi.org/10.1016/j.jpsychires.2012.09.008

Alger, S. E., Lau, H., \& Fishbein, W. (2012). Slow Wave Sleep during a Daytime Nap Is Necessary for Protection from Subsequent Interference and Long-Term Retention. Neurobiology of Learning and Memory, 98, 188-196. https://doi.org/10.1016/j.nlm.2012.06.003

Alger, S. E., Chambers, A. M., Cunningham, T., \& Payne, J. D. (2014). The Role of Sleep in Human Declarative Memory Consolidation. Current Topics in Behavioral Neurosciences, 25, 269-306. https://doi.org/10.1007/7854_2014_341

Barrett, T. R., \& Ekstrand, B. R. (1972). Effect of Sleep on Memory III: Controlling for Time-of-Day Effects. Journal of Experimental Psychology, 96, 321-327.

https://doi.org/10.1037/h0033625

Billiard, M. (2008). Normal Sleep. In H. R. Smith, C. L. Comella, \& B. Högel (Eds.), Sleep Medicine (pp. 9-24). Cambridge: Cambridge University Press. https://doi.org/10.1017/CBO9780511545085.003

Buzsaki, G. (1989). Two-Stage Model of Memory Trace Formation: A Role for Noisy Brain State. Neuroscience, 31, 551-570. https://doi.org/10.1016/0306-4522(89)90423-5

Centre for Educational Neuroscience, CEN (2017). Well-Rested children Do Better at 
School. Neuro-hit or Neuro-myth.

http://www.educationalneuroscience.org.uk/neuromyth-or-neurofact/well-rested-child ren-do-better-at-school/

Cirelli, C., \& Tononi, G. (2008). Is Sleep Essential? PloS Biology, 6, e216.

De Bruin, E. J., Van Run, C., Staaks, J., \& Meijer, A. M. (2017). Effects of Sleep Manipulation on Cognitive Functioning of Adolescents: A Systematic Review. Sleep Medicine Reviews, 32, 45-57. https://doi.org/10.1016/j.smrv.2016.02.006

Diekelmann, S., \& Born, J. (2010). The Memory Function of Sleep. Nature Reviews Neuroscience, 11, 114-126. https://doi.org/10.1038/nrn2762

Diekelmann, S., Biggel, S., Rasch, B., \& Born, J. (2012). Offline Consolidation of Memory Varies with Time in Slow Wave Sleep and Can Be Accelerated by Cuing Memory Reactivations. Neurobiology of Learning Memory, 98, 103-111.

https://doi.org/10.1016/j.nlm.2012.07.002

Drummond, S. P., Brown, G. C., Gillin, J. C., Stricker, J. L., Wong, E. C., \& Buxton, R. B. (2000). Altered Brain Response to Verbal Learning Following Sleep Deprivation. Nature, 403, 655-657. https://doi.org/10.1038/35001068

Durrant, S. J., Taylor, C., Cairney, S., \& Lewis, P. A. (2011). Sleep-Dependent Consolidation of Statistical Learning. Neuropsychologia, 49, 1322-1331.

https://doi.org/10.1016/j.neuropsychologia.2011.02.015

Euston, D. R., \& Steenland, H. W. (2014). Memories-Getting Wired during Sleep. Science, 344, 1087-1088. https://doi.org/10.1126/science.1255649

Feld, G. B., \& Diekelmann, S. (2015). Sleep Smart-Optimizing Sleep for Declarative Learning and Memory. Frontiers in Psychology, 6, Article 622. https://doi.org/10.3389/fpsyg.2015.00622

Fowler, M. J., Sullivan, M. J., \& Ekstrand, B. R. (1973). Sleep and Memory. Science, 179, 302-304.

Gais, S., Lucas, B., \& Born, J. (2006). Sleep after Learning Aids Memory Recall. Learning Memory, 13, 259-262. https://doi.org/10.1101/lm.132106

Genzel, L., Ahrberg, K., Roselli, C., Niedermaier, S., Steiger, A., Dresler, M. et al. (2013). Sleep Timing Is More Important than Sleep Length or Quality for Medical School Performance. Chronobiology International, 30, 766-771.

https://doi.org/10.3109/07420528.2012.763132

Gomez, R. L., Bootzin, R. R., \& Nadel, L. (2006). Naps Promote Abstraction in Language-Learning Infants. Psychological Science, 17, 670-674. https://doi.org/10.1111/j.1467-9280.2006.01764.x

Harvard Health (2012). Sleep Helps Learning, Memory. https://www.health.harvard.edu/blog/sleep-helps-learning-memory-201202154265

Harvard Health (2014). Too Little Sleep, and Too Much, Affect Memory. https://www.health.harvard.edu/blog/little-sleep-much-affect-memory-201405027136

Harvard Health (2017). The Health Hazards of Insufficient Sleep. https://www.health.harvard.edu/staying-healthy/the-health-hazards-of-insufficient-slee $\mathrm{p}$

Hill, C. M., Hogan, A. M., \& Karmiloff-Smith, A. (2007). To Sleep, Perchance to Enrich Learning? Archives of Diseases in Childhood, 92, 637-643.

Inostroza, M., \& Born, J. (2013). Sleep for Preserving and Transforming Episodic Memory. Annual Review of Neuroscience, 36, 79-102.

https://doi.org/10.1146/annurev-neuro-062012-170429 
Kopasz, M., Loessl, B., Hornyak, M., Riemann, D., Nissen, C., Piosczyk, H., \& Voderholzer, U. (2010). Sleep and Memory in Healthy Children and Adolescents-A Critical Review. Sleep Medicine Reviews, 14, 167-177. https://doi.org/10.1016/j.smrv.2009.10.006

Lahl, O., Wispel, C., Willigens, B., \& Pietrowsky, R. (2008). An Ultra Short Episode of Sleep Is Sufficient to Promote Declarative Memory Performance. Journal of Sleep Research, 17, 3-10. https://doi.org/10.1111/j.1365-2869.2008.00622.x

Lewis, P. A., \& Durrant, S. J. (2011). Overlapping Memory Replay during Sleep Builds Cognitive Schemas. Trends in Cognitive Sciences, 15, 343-351. https://doi.org/10.1016/j.tics.2011.06.004

Maquet, P., Laureys, S., Peigneux, P., Fuchs, S., Philips, C., Aerts, J., Del Fiore, G., Dequeldre, C., Meulemans, T., Luxen, A., Franck, G., Van Der Linden, M., Smith, C., \& Cleeremans, A. (2000). Experience-Dependent Changes in Cerebral Activation during Human REM Sleep. Nature Neuroscience, 3, 831-836. https://doi.org/10.1038/77744

Maret, S., Faraguna, U., Nelson, A. B., Cirelli, C., \& Tononi, G. (2011). Sleep and Waking Modulate Spine Turnover in the Adolescent Mouse Cortex. Nature Neuroscience, 14, 1418-1420. https://doi.org/10.1038/nn.2934

Mander, B. A., Santhanam, S., Saletin, J. M., \& Walker, M. P. (2011). Wake Deterioration and Sleep Restoration of Human Being. Current Biology, 21, R183-R184.

https://doi.org/10.1016/j.cub.2011.01.019

McDermott, C. M., LaHoste, G. J., Chen, C., Musto, A., Bazan, N. G., \& Magee, J. C. (2003). Sleep Deprivation Causes Behavioural, Synaptic, and Membrane Excitability Alterations in Hippocampal Neurons. Journal of Neuroscience, 23, 9687-9695.

Oudiette, D., \& Paller, K. A. (2013). Upgrading the Sleeping Brain with Targeted Memory Reactivation. Trends in Cognitive Sciences, 17, 142-149.

https://doi.org/10.1016/j.tics.2013.01.006

Payne, J. D., Tucker, M. A., Ellenbogen, J. M., Wamsley, E. J., Walker, M. P., Schacter, D. L., \& Stickgold, R. (2012). Memory for Semantically Related and Unrelated Declarative Information: The Benefit of Sleep, the Cost of Wake. PLOS ONE, 7, e33079. https://doi.org/10.1371/journal.pone.0033079

Peigneux, P., Laureys, S., Fuchs, S., Collete, F., Perrin, F., Reggers, J., Philips, C., Dequeldre, C., Del Fiore, G., Aerts, J., Luxen, A., \& Maquet, P. (2004). Are Spatial Memories Strengthened in the Human Hippocampus during Slow Wave Sleep? Neuron, 44, 535-545.

Plihal, W., \& Born, J. (1997). Effects of Early and Late Nocturnal Sleep on Declarative and Procedural Memory. Journal of Cognitive Neuroscience, 9, 534-547. https://doi.org/10.1162/jocn.1997.9.4.534

Rasch, B., \& Born, J. (2013). About Sleep's Role in Memory. Physiological Reviews, 93, 681-766. https://doi.org/10.1152/physrev.00032.2012

Ribeiro, S., \& Stickgold, R. (2014). Sleep and School Education. Trends in Neuroscience and Education, 3, 18-23. https://doi.org/10.1016/j.tine.2014.02.004

Schulz, H. (2008). Rethinking Sleep Analysis: Comment on the AASM Manual for the Scoring of Sleep and Associated Events. Journal of Clinical Sleep Medicine, 4, 99-103.

Stickgold, R. (2013). Parsing the Role of Sleep in Memory Processing. Current Opinion in Neurobiology, 23, 847-853. https://doi.org/10.1016/j.conb.2013.04.002

Talamini, L. M., Nieuwenhuis, I. L., Takashima, A., \& Jensen, O. (2008). Sleep Directly Following Learning Benefits Consolidation of Spatial Associative Memory. Learning Memory, 15, 233-237. https://doi.org/10.1101/lm.771608 
Tononi, G., \& Cirelli, C. (2003). Sleep and Synaptic Homeostasis: A Hypothesis. Brain Research Bulletin, 62, 143-150. https://doi.org/10.1016/j.brainresbull.2003.09.004

Tononi, G., \& Cirelli, C. (2006). Sleep Function and Synaptic Homeostasis. Sleep Medicine Reviews, 10, 49-62. https://doi.org/10.1016/j.smrv.2005.05.002

Tononi, G., \& Cirelli, C. (2014). Sleep and the Price of Plasticity: From Synaptic and Cellular Homeostasis to Memory Consolidation and Integration. Neuron, 81, 12-34. https://doi.org/10.1016/j.neuron.2013.12.025

Tucker, M. A., \& Fishbein, W. (2009). The Impact of Sleep Duration and Subject Intelligence on Declarative and Motor Memory Performance: How Much Is Enough? Journal of Sleep Research, 18, 304-312.

Vyazovskiy, V. V., Cirelli, C., Pfister-Genskow, M., Faraguna, U., \& Tononi, G. (2008). Molecular and Electrophysiological Evidence for Net Synaptic Potentiation in Wake and Depression in Sleep. Nature Neuroscience, 11, 200-208. https://doi.org/10.1038/nn2035

Wagner, U., Gais, S., Haider, H., Verleger, R., \& Born, J. (2004). Sleep Inspires Insight. Nature, 427, 352-355. https://doi.org/10.1038/nature02223

Watson, B. O., \& Buzsaki, G. (2015). Sleep, Memory and Brain Rhythms. Daedalus, 144, 67-82. https://doi.org/10.1162/DAED_a_00318

Wilhelm, I., Rose, M., Imhof, K. I., Rasch, B., Buchel, C., \& Born, J. (2013). The Sleeping Child Outplays the Adult's Capacity to Convert Implicit into Explicit Knowledge. Nature Neuroscience, 16, 391-393. https://doi.org/10.1038/nn.3343

Wilson, M. A., \& McNaughton, B. L. (1994). Reactivation of Hippocampal Ensemble Memories during Sleep. Science, 265, 676-679.

Yang, G., Lai, C. S., Cichon, J., Ma, L., Li, W., \& Gan, W. B. (2014). Sleep Promotes Branch-Specific Formation of Dendritic Spines after Learning. Science, 344, 1173-1178. https://doi.org/10.1126/science.1249098

Yaroush, R., Sullivan, M. J., \& Ekstrand, B. R. (1971). Effect of Sleep on Memory II: Differential Effect of the First and Second Half of the Night. Journal of Experimental Psychology, 88, 361-366. https://doi.org/10.1037/h0030914

Yoo, S. S., Hu, P. T., Gujar, N., Jolesz, F. A., \& Walker, M. P. (2007). A Deficit in the Ability to Form New Human Memories without Sleep. Nature Neuroscience, 10, 385-392. https://doi.org/10.1038/nn1851 